\title{
Environmental Liability Insurance as a Handmaiden to International Trade and Investment
}

\author{
by Mark W. Pauly*
}

\section{Introduction}

There are two important economic propositions which underlie this paper. The first is that free trade and investment across international boundaries, unimpeded by structural or regulatory restrictions, is generally in the best interest of citizens of all nations. The second is that it is efficient to insure large random losses. In what follows I want to apply these two propositions, first in theory and then with some empirical applications, to the analysis of the impact of insurance against the losses arising from large scale environmental liabilities in a world in which there is international trade in the products whose production may generate those liabilities and international investment in the facilities to produce those products. In addition, I will consider a world in which there is likewise international trade in insurance and international investment in insurance capacity.

After all, the specific application that stimulated Daniel Bernoulli to develop expected utility theory was marine insurance. He realized that the purchase of implicit insurance by shippers (even unfair insurance) helped persuade them to load their goods on a ship bound for other countries.

My analysis will proceed in two steps. First, I will set out a simple conceptual model in which two trading countries both produce goods where production potentially can cause environmental costs. I first model this situation without insurance, then show the impact of insurance availability, and finally add some considerations of investment in production of those commodities and of trade and investment in insurance. The second step examines some current problems in environmental liability coverage and policy, to see the impacts, considering the requisites of international trade and investment on those issues.

\section{The role of insurance}

Insurance is an important part of many economies. In the United States, for example, insurance premiums of all types equal approximately 9 percent of gross national product, and insurance employment accounts for 2 to 3 percent of total employment. Insurance that is traded internationally is of less importance as a percentage, amounting to only about 2 percent of total premium volume in the US. In some smaller countries, the proportion is higher (especially, for example, in Switzerland), but in general it is not large (Kunreuther and Pauly, 1990).

\footnotetext{
* Health Care System and Insurance Depts, University of Pennsylvania, Wharton School, Philadelphia.
} 
However, it may be reasonable to suppose that both insurance overall and trade in insurance are much more important to the world economy than the employment and export statistics suggest. In particular, insurance may be a sine qua non for production and export of commodities with the potential to cause risks and losses. Somewhat more speculatively, one might suppose that international trade in insurance, especially in reinsurance, is a key element in "topping off" protection against large losses without which production of some commodities in some countries cannot occur.

In what follows I set out some conceptual considerations dealing with the performance of these functions. I also deal with the evaluation of the efficiency with which these functions are performed.

\section{The model}

Assume that there are two products that can in principle be produced in any country and traded internationally. One product, $Z$ raises no issues of environmental risk, and is produced under constant returns to scale at a cost of $C_{Z}^{i}$ in country $i$. The other product $X$, is produced under constant returns at a cost $C_{X}^{i}$, subject to a loss of $\$ L^{i}$ per unit in country $i$ with loss probability of $p^{i}$. For the present, we will assume that $L^{i}$ represents both the legal liability in country $i$ and the actual amount of the damage. The per unit cost of $X$ in country $i$ can then be represented as $C_{X}^{i}+p^{i} L$.

This formulation of the problem makes the chances of an accident (e.g., a spill) depend linearly on total production. We assume initially that $X$ is also produced subject to constant returns to scale, and that "plants" are therefore small and numerous.

$A$ two country model. We assume that there are two countries, $A$ and $B$, with each country having an absolute advantage in one of the products. Thus $C_{Z}^{A}<C_{Z}^{B}$ but $\left.C_{X}^{A}+p^{A} L^{A}\right\rangle$ $C_{X}^{B}+p^{B} L^{B}$. All firms are owned by residents; both manufacturing firms and insurance firms in country $X$ must obtain capital from investors who are residents of country $X$. It therefore follows that, if there is a nonzero demand for $Z$ and $X$ at prices $P_{z}=C_{X}^{A}$ and $P_{X}=C_{X}^{B}+$ $p^{B} L$, both commodities will be consumed in both countries, while country $A$ will specialize in production of good $Z$ and country $B$ will specialize in production of good $X$.

Why might there be a demand for insurance against the loss $L$ ? We need to assume both that owners of firms are unable to achieve diversification in their portfolios and that they are risk averse. In such a case, without insurance, the supply price for $X$ will be $C_{X}^{B}+$ $p^{B} L^{B}+R^{B}$, where $R^{B}$ is a risk premium greater than zero. Suppose that insurance could be made available at a premium per unit of output of $\Pi^{B}=p^{B} L^{B}+S^{B}$ and $S^{B}<R^{B}$, where $S^{B}$ is the administrative loading cost. In such a case, if $p$ and $L$ do not change as coverage changes, insurance would be preferred. The welfare gain from introducing insurance depends on the difference between $S^{B}$ and $R^{B}$ and on the demand elasticity for $X$ (which we will assume is the same in both countries).

This says that insurance is welfare increasing to a greater extent if:
a) output of the product is large
b) owner risk aversion is high
c) loading is low
d) demand for the product is more elastic. 


\section{Some modifications}

This simple model shows that improvements in markets for insurance can not only increase the welfare of the risk averse persons buying insurance (capital owners) but also the welfare of consumers in all countries. However, the model of many firms bearing risks which are small in absolute terms (though perhaps large relative to owners' wealth) is somewhat unrealistic as a characterization of environmental risks. (This is not to deny that many environmental risks were caused by multiple decisions of many firms - a typical case for water pollution or some kinds of hazardous materials/superfund issues.) What if there are economies of scale up to a size of firm which is large relative to the country concerned? In this case, both single firm decisions and single firm events can trigger absolutely large losses and large liabilities. How should we think of this in a model of international trade?

The large firm raises the possibility of monopoly market power; the price of good $X$ may not settle to its marginal cost plus expected loss per unit. This can change the overall terms of trade between the two countries, and could mean that, compared to a competitive equilibrium, owner-residents of the country in which the risky product is produced could be better off. However, even in this case, the availability of insurance should generally be to everyone's benefit - even if the final equilibrium is not one of full economic efficiency. How much if any lower premium might be transferred to consumers depends on the demand elasticity for the product, however.

The most important difference, however, is that there might now be the possibility of a single large loss, and our assumption that insurance will be available at premiums just above the expected loss and the administrative cost may no longer hold. There may be insurance capacity problems in country $B$, if its investors alone provide the insurance financial instrument. Accordingly, it may be efficiency improving if there is an international market in insurance as well, with investors in both countries putting up their capital to cover any environmental losses (Tyran and Zweifel, 1993; Meyer, 1996). Conversely, government restrictions which prevent full participation in risk sharing will reduce welfare.

Another possible modification concerns the relationship between the legal loss and the actual loss. We have assumed, so far, that owners of capital are responsible for the actual damage done. But what if a country's legal system permits the loss levied on the firm to be greater than the actual loss (e.g., by awarding treble damages for accidents following alleged but not actual negligence)? The cost of good $X$ will be artificially increased. We know for certain that welfare will be reduced in the importing country, and probably will be reduced (or not increased) in the exporting country as well. Likewise, excessive awards may compound the problem of insurance availability.

I have little more to add on this matter, other than to say that excessive damage awards will reduce the real volume of trade, and are to be deplored. If we can identify countries with legal systems more conducive to such excessive awards, we should find some diminution in the size of their exports of risky products (as well as in their total production). However, excessive awards may be politically popular if the country has some market power.

The third modification concerns bankruptcy. There are several influences at work here. First, the possibility of using bankruptcy to limit liability could mean that the price of the product will not cover the full loss. The portion of loss that exceeds the firms' assets will not be incorporated into their prices. There may be greater exports, when bankruptcy protection is possible, but overall welfare of citizens of the producing country is likely to suffer, 
while that of importing countries will gain. Second, and to some extent offsetting, if bankruptcy has an administrative cost of its own, its possibility may increase both the demand for and the importance of insurance to the firm. Where bankruptcy is costly, limits on insurance capacity will have stronger effects than where bankruptcy is cheap.

Moral hazard is another possibility (Zweifel, 1996). Even if the law imposes the correct liability, the presence of insurance may cause firms to skimp on efforts to restrict or control damages. However, moral hazard will occur only if the insurer is unable to detect such changes in behavior. Moreover, since moral hazard will cause an increase in EIL insurance premiums, there will be a deterrent to insurance coverage (and a rise in the price of the risky product). If insurance is purchased voluntarily, there may be greater environmental risk with insurance than in its absence, but this loss will be offset by a gain in well being to the risk averse owners of the producing firm. That is, insurance may reduce the effectiveness of taxes or tort liability in reducing environmental damage, but it does not reduce economy wide efficiency, even when moral hazard is present. Of course, if the owners of capital in the firm producing $X$ in country $B$ are not citizens of country $B$ there is the usual ambiguity about whether their welfare should count.

Finally, the environmental risk may extend across country boundaries. Suppose that, if an accident occurs in the production of a risky product in country $B$, damage is also done to lives and property in country $A$. If the legal system attenuates or ignores the risk that occurs to foreigners, again the price of the product will be lower, production and exports higher, but now everyone can be worse off from an externality not properly adjusted through the legal system compared to what would happened if it were treated properly. This will be expanded on below.

\section{Some qualitative considerations}

We first match this theoretical discussion of the value of trade and insurance with what we know or can know about institutional and political structures. One observation is that, relative to total GDP and national markets, neither the production of hazardous commodities nor the premium paid for EIL insurance are large.

These observations imply that, if the worst case scenario was an accident that completely wiped out all plant and equipment in an industry in a country, the insurance industry in that country could generally handle both coverage and payment for the losses. However, astute observers will note, the liability correctly assessed on these firms in the case of an environmental catastrophe frequently exceeds the value of their plant and equipment. No rational firm owner, not even a very risk averse one, would voluntarily buy coverage for more than the value of his assets. So often the requirement to purchase coverage against very large (sómetimes open ended) losses must be imposed by the government.

Such a potentially large and unpredictable liability is presumably the reason why insurers sometimes say that they have insufficient "capacity" to furnish insurance at any reasonable premium. That is, it is hard not to believe that insurers have the capacity to cover all the capital of any single firm, even a large global firm such as Exxon or Union Carbide. But the damage that an environmental accident can cause can be greater than the value of the firm's assets. Thus some countries require firms to have insurance coverage against such catastrophic losses, and to incorporate this premium as part of their cost of doing business. Such laws ensure that consumers of the product will bear the full cost of risk. 
Here again the extent of the problem is constrained both by limits on consumer demand and the possibility of importation. Indeed, if a very strict liability law or legal interpretation makes a country's cost of producing hazardous products exorbitantly high, there is an easy solution - produce none of the products domestically, and import the products from countries with less stringent rules. More generally, if production imposes risks on the surrounding population, the richer that population is, the less likely their country will maintain a viable or growing industry producing dangerous products.

From the viewpoint of economic efficiency, this is exactly as it should be. However, those with a sense of global equity may be upset by the outcome. Note, however, that citizens of the country that does produce the risky product are compensated for their risk.

Sustainability. It is less obvious whether the equilibrium solution in a regimen of international trade - even though it is economically efficient - will be consistent with sustainable development, despite the commitment of some of the largest firms in the industry to the preservation of the environment (Steering Committee, 1995).

The problem, of course, is that markets produce an efficient solution taking into account the preferences of the current (adult) generation. The interests of the future, the concerns for compromising "the ability of future generations to meet their own needs", is only as strong as the concern that current generation has for future generations. Consequently, the efficient and/or competitive level of protection against environmental risks that may have effects across generations will also vary across countries. Since virtually any action associated with producing dangerous products runs some non-zero risk of "compromising" sustainability, it would obviously be inefficient (and would probably be impossible) to produce some products without affecting, to some small degree, the risk of compromising the potential welfare of future generations. More importantly, if international markets are competitive and there are no internationally enforced sanctions on actions which increase shortterm profits at the expense of future development, individual insurance firms, as well as individual countries, can limit their own behavior and the behavior over which they have control. But then production of dangerous products will simply move to those places with less strict rules or no rules. It is not even obvious whether in some (literally) global sense, a partially enforced policy of sustainable development is better than no policy at all.

Countries choose social institutions, in the form of regulation and legal liability, for reflecting their concerns for sustainability. Their choices will reflect the degree of concern, their attitude toward risk, and their definition of the level of "needs" that future generations should be able to meet. Probably the minimum level of needs chosen in a currently lowerthan-average income country will be lower than the level chosen in a richer country. Here again, analysis leads to the conclusion that, in a regime of international trade and investment, dangerous products will tend to be produced in countries.

\section{Political realities and insurer reaction}

These thoughts lead to the conclusion that hazardous products will tend to be produced in countries where (1) the loss borne by the firm producing the product is least, and (2) where it is best pooled via insurance. If all governments around the world assessed liability optimally, and if bankruptcy were not an issue, this optimal equilibrium might also appear 
to be socially acceptable. Products which are virtual necessities would still be produced, usually in settings in which the input costs are relatively low, environmental risk is reduced by environmental factors, and at-risk property and health are of low value.

Less palatable is the notion that, for a given degree of potential for physical damage, that damage will tend to occur in countries that impose the smallest legal liability. The problem here is that there is obviously no strong basis for believing that the politically chosen level of liability equals the actual money value of harm done to a country's property and citizen health. Insurance will reduce the effect on prices of any level of legal liability, but it cannot correct a fundamental error in the establishment of the initial level of liability, whether that error comes from an honest regulatory mistake or a conscious political choice.

Is there evidence that legal liabilities are not correctly set? They may either be too high or too low. Many believe that the level of expected legal liability gets set too high in countries, such as the US, which are highly litigious. Conversely, countries competing for international investment may overestimate the improvement in money income for workers and property values for all that would accompany artificially low levels of liability. The latter case is to some extent self-correcting, since the losses to property that will actually occur if an accident happens will exceed what the legal system can award, but will still be borne by someone in the country.

However, the process for valuing losses and setting legal liability for the valuation of lives or health is most difficult. Under many methods of attaching money values to life, lower values will be attached to persons who are less productive and/or have low income. Some persons will have ethical problems with this process. One solution is to determine what persons would need to receive in the case of an accident, to get them to agree to accept an environmental risk, but we know that this is an imprecise science.

What can we then say if production of dangerous commodities gravitates to certain countries that appear to some observers to set suboptimal liability standards and/or regulatory rules, environmental taxes, or legal liability? We can offer the small hope that insurance will at least make prices in countries that do set optimal standards as competitive as they can be. We can note that, to control income, some countries do truly regard their cost of risk to be lower than that of others, and it is not clear that the country that sets the highest value on life has necessarily made the better choice. So not all variation is suspect.

Probably the strongest reason for the feeling of uneasiness is the feeling that values placed on life even by the legal and regulatory process of a country depend on income levels in that country. Within countries, suitable redistribution can deal with some of this variation. Across countries, those with lower average incomes may value to risk associated with dangerous products at a lower level.

What can international investors and international firms do if they believe some country is setting its liability standards too low? I first need to emphasize the word "belief". Although everyone has some rough idea of liability standards that are too strict or too lenient, reliable and valid techniques for quantifying optimal liability levels do not exist. This necessarily means that judgements about the adequacy of liability will be subjective. Note also that these judgements are most important, from an international perspective, about countries that tend to set standards too low. That is because, as argued above, business and investment will naturally gravitate toward low cost countries. To be sure, liability 
cost is not the only element of cost, and qualitative aspects of output and service will matter as well, as will local labor productivity. It appears, however, that there is relatively little in the way of external incentives that will help.

In countries where liability is set too high, in contrast, the problem tends to be self-limiting. National investors and national insurers may be concerned, but eventually higher liability cost will drive out investment in production of dangerous products, and with it the potential for loss. Any process of transition from a low to high liability level may raise concerns, however.

Should an insurer cover, and should a reinsurer add to its portfolio, exposures for environmental liability in countries in which the legal standards appear to be low? Since the insurance market is competitive, low liability most probably means lower insurer premiums, not higher insurer profit. There is, however, a threat. If an environmental accident occurs, those parties who suffer loss not covered by legal liability may, nevertheless, affect insurers, in two ways. The most obvious ways is if some affected firms or citizens have first party coverage for those losses excluded from third party legal liability. From an economic viewpoint, internalizing the cost of such losses will be more complete the fewer the number of insurers and the more they share losses. This, at least, means that loss-deterrant activities would be reevaluated. Those at risk may engage in protective measures, but it may be hard to arrange a Coasian bribe if protection at the source of pollution is more efficient. A less obvious consequence is that angry and inadequately compensated citizens may lobby for ex-post facto establishment of liability or for transfer payments from the government.

\section{Trans-boundary issues}

Much the same argument holds for risks whose consequences (but not legal liability) flow across country boundaries. Absent any insurance coverage, firms will ignore their spillover costs, and dangerous products in international trade will tend to be produced where spill-overs are maximized. If each country follows this policy, and if relative costs are roughly the same worldwide, all countries can end up worse off. Small countries will be more likely to generate spill-overs than large ones.

Without international agreements on liability or protection, the results look hopeless. But are they? Perhaps not entirely, if losses are insured and insurers are able to internalize losses to some extent. Consider the extreme case in which a single insurer covers both the liability within the country and the (first party) spill-over harm experienced in the neighbor. If the insurer is permitted to use its own resources to affect loss probabilities, it will spend to implement such loss reduction policies. This assumes that both regulation and the firm's organizational structure do not interfere. Things are somewhat more complex if there are multiple insurers. To the extent that these insurers all reinsure with the same firm perhaps there will be some internalization. That is, insurers may come to notice that their EIL claims per unit of coverage in country $X$ (which is either a small country or has plants closer to its borders) are lower than claims from large country $Y$, but that claims for first party losses from firms surrounding country $X$ are greater than for those surrounding country $Y$. They may then offer rewards, in form of lower premiums conditional on abatement.

This assumes, of course, that the loss imposed on those to whom effects spill-over is also insured by the same insurer. To the extent that such losses are triggered by specific events ( $a$ 
sudden release of pollutant), and cause property damages, they will be likely to be covered. If they cause medical care costs or increases in overall mortality, they often will not be covered.

Nevertheless, the rise of multinational insurers at least raises the possibility that some of the spill-over will be internalized. Is it conceivable that insurers will respond to the incentives, again in the Coasian sense, to bribe the polluter to move closer to the globally optimal level of pollution abatement whether that takes the form of protection, moving or closing the plan, or (at least) reducing output? I believe that the answer is yes in theory.

The argument is as follows. Suppose an insurer covers damages from production of a dangerous product in both countries, but suppose a polluter in one country has only assessed of the cost of damages done in that country, not the cost of harm done in adjacent countries. Initially, it would appear that this arrangement would lead to higher production than is efficient. However, if the insurer also covers losses in the adjacent country, it will find its advantages to "bribe" the polluter to lower production ot install protection (in the form of lower premiums conditional on these adjustments).

Could this single cross-country insurer be replaced by country-specific insurers? The answer is negative; firms in the polluting country will prefer insurance with rewards for pollution reduction, and firms and citizens in the receiving country will prefer the lower premium (and less damage) that can be guaranteed by the cross-national insurer.

There are two potential flaws in this happy story. One is related to myopia, and one is related to competition among numerous insurers.

The myopia argument primarily affects insurance markets in the harmed country. Suppose that a cross-national insurer has been engaged in activities to reduce cross-border pollution. If an entrant in the harmed country can convince itself and its customers that the low levels of pollution will prevail if it takes all of the business and offers no bribes, it will be able to offer a more attractive premium. Of course, if it does so, it will eventually lose money.

The other case is one in which there are multiple cross-national insurers. Here payment to a firm to reduce pollution will spill over to customers of other insurers. A more concentrated market can avoid this problem. But so can a reinsurance pool, in which the firms sharing the reinsurance see that it is in their collective interest to offer incentives for lower pollution. The key issue then is whether such a pool can be arranged.

\section{Two applications}

In this section I explore two applications for adding the possibility of international trade in products and insurance to two recently discussed issues in international environmental liability insurance: the Montreal Protocols and the Tatshenshini River case.

The Montreal Protocols dealt with the effect of chlorofluorocarbons (CFCs) on the global ozone shield, while the Tatshenshini River case dealt with downstream pollution in Alaska from a planned upstream copper mine and smelter in Canada. Effects in one case spill over to all other countries, and are "reciprocal", whereas in the other case the effects involve only two countries and are one way.

Both cases involved much more general issues on the value of the environment and environmental politics, but both also would have been affected by trade in insurance and goods in ways not fully appreciated. 
Let me deal with the Tatshenshini River case, or one like it. It seems reasonable to assume that the cost of producing copper, ignoring environmental risks, would be low enough in Canada that it would become a net exporter. That is if the burden of the argument that development by commercial firms was possible. But what damages are taken into account?

For the moment, assume that the mine can only have one level of production if it produces at all. Also, assume for the moment that we can develop an accurate measure of the downstream harm done in Alaska. Then we need to consider two possibilities: trade is feasible at a cost that includes the cost of the harm, or trade is not feasible.

If trade is feasible, then no damage is done to global efficiency if production and trade are combined. Insurance may assist in achieving this feasibility. The gains to owners of inputs in Canada and to customers for copper worldwide will more than offset any harm done in Alaska. However, this may be small consolation for people in Alaska, and a transfer may be desired on equity grounds.

Now suppose that costs of environmental damage are high enough that, if the mine were made liable for environmental risk downstream, development will not pay. It is obvious that the patterns of international trade will then depend on whether or not liability is imposed. The imposition of liability in turn will depend on the state of international liability law. Such law does exist but, as the authors of the definitive study note (Paisley and McDaniels, 1995), its effectiveness in terms of sanctions depends on the voluntary cooperation of the damaging country.

Interestingly, the actual process in the Tatshenshini River case to date has apparently not been much affected by considerations of legal liability, but rather has taken the form of a debate over regulation: permits and rules about siting and discharge of pollutants have been more important.

It would be a virtual tautology, but still perhaps a useful point, to conclude that if the developers of the mine were liable for downstream damages and if those damages were properly assessed, there would be little need for specific regulation to achieve efficiency. (Political consensus is another thing entirely.) If some of those damages could be caused by risky events, insurance against liability would further assist efficiency, although it would surely make development more likely than in its absence.

Conversely, if liability were not assessed or set too low, inefficient development might occur. Moreover, insurance might be harmful, since it may assist in such a process. Even in this case, however, if the same insurers covered upstream third party liability and downstream first party damages, the correct outcome might ensue. However, an insurer that did not do business in the downstream country might have an advantage in terms of pricing to the upstream firm, so we should not be too quick to conclude that international insurance would help matters.

The real dilemma in these cases is that of accurately quantifying the amount of (prospective) downstream harm, especially when (as in this case) the amount of downstream development is currently small but might be large in the future. In principle changes in land prices should reflect impacts on the profitability of future development opportunities, but harm to the prices of undeveloped land is not typically insured by liability insurance. 
What if a single insurer covered the copper mine in Canada and the downstream landowners in Alaska? This insurer would make sure efficient precautions were taken. It would not eliminate the harm to landowners' property values, but that would only be a matter of redistribution. However, it is hard to see how this approach can help to affect an all-ornothing decision like siting. But perhaps that case is really not so relevant - something would be developed at the Tatshenshini River site; it is only a matter of what.

The discussion of the Montreal accords also turned on the question of damage assessment. (The actual process implemented somewhat differed from the accords.) In order to get less developed countries (LDCs) to agree to a ban on future production of chlorofluorocarbons, they were to be compensated for the harm they suffered to some extent. This particular example, of a slowly developing process of environmental harm, would probably not fit well within an insurance/liability framework. But let us use it as an example of a liability that is truly "global public", that affects everyone in all countries equally. What impacts on trade and insurance would be expected to occur?

The first point is that production of the dangerous commodity would, in the absence of trans-national liability, be concentrated in some countries. The analysis of the Montreal accords noted that the growth of production of CFCs was not uniformly distributed across countries; some (such as China and India) had rapidly growing production, while others (such as Yugoslavia even before its breakup) had declining production. These numbers remind us that, in countries with protectionist policies such as India and China, production of dangerous commodities can well be higher than under free trade.

The second point is that internalizing the externality through an international insurance market would, in such a case, literally require global cooperation and global reach, which probably would be more difficult than the bi-country example discussed above. Moreover, international liability law would probably not be able to bear the burden of such multiple adjustments. The process implemented in the Montreal accords, in which LDC's steps to reduce risk were subsidized, would not be accomplished by a simple liability/insurance arrangement, even one that imposed accurate damages. In contrast, if all countries were or were thought to be of equally capable of tolerating risk reduction, then in principle a system of liability and/or a global insurance-reinsurance pool could deal with the problem.

To sum up: the main difference between a two country and a global reciprocal liability setting is not so much the capability of legal systems or of insurance markets - although both would be somewhat more challenged in the many-country case. The real problem is the disparity of wealth among countries. This means that the willingness by of a low income country producing dangerous commodities to accept legal liability for harms, (cross boundary or direct) is probably limited. In principle, of course, a bribe to reduce risk, is an alternative to liability but the institutional structure to offer such side payments is more likely to resemble the structure set up under the Montreal Accords than the workings of either legal liability or insurance arrangements.

\section{Dealing with uncertainty about risks in a global economy}

One of the fundamental problems in dealing with environmental hazards is the great uncertainty about their likelihoods and their consequences. It is probably fair to say that if (contrary to fact) it were possible to develop measures that were objectively correct and believed by all stakeholders to be so for both the probabilities of large scale accidents and 
their consequences that many of the problems, political and economic, would go away. But this uncertainty and imprecision seems unlikely to be eradicated soon. In a world where stakeholders have opinions about facts, what difference do the international trade and investment aspects just discussed actually make?

Let us first consider the environmental risk itself. Suppose that everyone agrees that the production of some commodity poses an increased probability for some environmental harm, but citizens in different countries disagree on the likelihood and consequences of this harm. In line with our earlier analysis, it might seem that, other things equal, production would occur in the most optimistic communities.

However, the development of a world market in insurance may actually inhibit such judgement-based specialization when firms are liable for losses. The reason is this: even if firms and citizens of one country discount the likelihood of accidents in a given production process, as soon as they turn to the world market for insurance, they will be confronted with premiums that reflect the world insurance markets' attitude toward the risk. It is true that the most optimistic underwriter will tend to get the business. However, even though there may be some variation among insurers, it is likely to be less than the variations among investors.

The result is that in countries in which investors are above-average in optimism, insurance will appear to be overpriced. If legal rules do not require coverage, producers will therefore be more likely to be uninsured in precisely those countries in which production will concentrate. In contrast, if insurance coverage is required, premiums will have to be paid and production will not be greater. The key issue then is whether or not insurance against the loss can be declined. If so, investor evaluations do not matter - only insurer evaluations. The result will be no different than it would be if everyone had the same beliefs about risk.

Mutual insurance is often an efficiency-improving institution in markets in which people have different beliefs about risk (as long as they can agree on classifying risks into homogeneous groups). However, when international trade occurs, mutual insurance will harm rather than help efficiency. In the first case, production will be even lower in the country in which investors have overly-optimistic expectations and reassure themselves with mutual insurance. In the second case, if mutual insurance qualifies for legal protection, it will substitute the erroneous judgements of optimistic local investors for the more tempered judgement of global-market insurers.

\section{Conclusion}

The overall theme of this paper is that efficient global markets in insurance produced by firms operating in many countries can offer some strong advantages. Some of those advantages are the traditional ones of free trade, although the implicit economies of scale possible with large insurance risk pools are a somewhat different idea. The model of trade alternative to comparative advantage - the network economies model - also seems to be enhanced by global markets in insurance.

More generally, if we view the market equilibrium as encompassing all of the information possessed by the experts in the market, we can see an additional rationale for a global insurance market. It is a way of pooling knowledge about risks as well as the risks themselves. It can help tp prevent errors, and it can help to deal with externalities, both in 
ways that do not require direct intervention by an omniscient government. Governments, however, must all do their job - that of imposing correct environmental liability. My an alysis does not suggest that governments can disappear, but does suggest that their role can be limited to the enforcement of rules, rather than to the more daunting tasks of analyzing data and making resource allocation decisions.

\section{REFERENCES}

ALLEN, H. F., FERNANDO, C.S., KLEINDORFER, P. R. and ROSENTHAL, I., "Issues and Options in Implementing the Montreal Protocol in Less Developed Countries: A Research-oriented Perspective", CRDP, Wharton School, University of Pennsylvania, July, 1991.

COASE; R., "The Problems of Social Cost", Journal of Law and Economics, October 3, 1960, pp. 1-44.

KUNREUTHER, H. and PAULY, M. V., International Trade in Insurance. (Richard D. Irwin, Inc.: Homewood, IL, 1990.)

MEYER, B., "The Insurance of Natural Hazards: Proposals to an Appropriate Risk Partnership Between Insurers, Reinsurers, The Government and Policyholders", Geneva Papers on Risk and Insurance, 80, 1996, pp. 393-400.

SMITH, C. and MAYERS, D., "On the Corporate Demand for Insurance", Journal of Business, 55:2, April, 1982, pp. 281-296.

PAISLEY, R. K. and McDANIELS, T. L., "International Water Law, Acceptable Pollution Risk, and the Tatshenshini River", Natural Resources Journal, 35, Winter, 1995, pp. 111-132.

Steering Committee, "Statement of Environmental Commitment by the Insurance Industry", Cologne, September, 1995.

TYRAN, J. R. and ZWEIFEL, P., "Environmental Risk Internalization through Capital Markets (ERICAM): The Case of Nuclear Power", International Review of Law and Economics, 131, 1993, pp. 431-444.

ZWEIFEL, P., "The Contribution of Environmental Impairment Liability Insurance to Eco-Efficiency", Geneva Papers on Risk and Insurance, 80, 1996, pp. 336-340. 